\title{
Understanding Dynamic Engagement of Community in Local Governance, Enhancing Grassroots Development in South Africa
}

\author{
Andrew Osehi Enaifoghe $e^{1}$, Cotties Toyin Adetiba ${ }^{2}$ \\ ${ }_{1}^{1}$ Department of Public Administration, University of Zululand, KwaDlangezwa, South Africa \\ ${ }^{2}$ Department of Politics and International Studies, University of Zululand, KwaDlangezwa, South Africa \\ andyransey@gmail.com
}

\begin{abstract}
The discourse on "Community engagement and commitment" is a critical subject that requires the interest of individuals within communities to fully participate in activities that address community needs. A meaningful citizen engagement reaches out beyond physical inclusion to incorporate the generation of thoughts and deliberations. In addition, it includes the commitments to leadership process in decisionmaking and the involvement of community members in the administrative responsibility. Among the elements that propel individuals to take an interest to participate in local governance need to assume a functioning role in bettering their very own lives, satisfying social or religious commitments feeling a need for a sense of community, and other quantifiable benefits. This study conceptualizes what community engagement, models, and frameworks is about and that can be used as a guide, to inspire communities in meeting various challenges relating to their interest in participation and cooperation. The study does not claim to cover all the accessible and significant human sociology on public cooperation literature. Qualitatively, the study gave an outline of the basic ideas that shed light on community participation, cooperation and commitment to duty and responsibility. As the study adopted a qualitative approach, mostly secondary source was consulted to address the research question. The findings show that the instrumental way to deal with citizens' concerns, with attention to results and adequacy is considerably more far-reaching than the more transformative method. Furthermore, people ought to review challenges related with gathering politicization of improvement and participatory structures, the absence of responsibility towards organizing community interest, the absence of limit capacity among partners, poor access to data or information, and inability to perceive and work intimately with community-based associations. It was then recommended that the community and different partners take part in the discussions that prompted the last record, as this is required by the South African Municipal Structures Act.
\end{abstract}

Keywords: Dynamics, transformative, governance, participation, community, leadership, states, citizens.

\section{Introduction}

The process where a community directly participate in local governance with the commitment of common citizens or community members in the issues of planning, administration, basic leadership of making decisions and the general improvement programs at local or grassroots dimension, has recently turned into an essential part of democratic practice. On such account in South Africa where local citizens interest to participate in local government administration has actually turned out to be synonymous with genuine administration (John, 2006). In such manner, the South African Municipal Structures Act, Chapter 4, subsections (g) and (h) give the 'official municipal managers to write an annual report about the involvement of the community associations in the issues of the region and guarantee that due respect is given to public perspectives and provide details regarding the impact of counsel on the choices of gathering' (Local Government: Municipal Structures Act, Republic of South Africa (RSA), 1998). Nonetheless, it appears that most community support practices in post-Apartheid South Africa are to a great extent observer of legislative issues.

Where common individuals have for the most part progressed toward becoming endorsees of pre-structured arranging programs, are frequently the objects of regulatory control. A phenomenon of compromise in the global field of "consensus politics whilst state functionaries of both the pre- and post-apartheid eras ensconce themselves as bureaucratic experts summoned to ensure a better life for all" (Tshoose, 2015). Apparently, the procedure, objective and missions of a progressively even-handed society work only as "promissory notes issued" like clockwork during the campaign for elections (Glavaš, 2017). Over the past years, the specific idea of community support has been to a great extent decreased to an awkward custom or ritual a vital 
informative supplement required by the different laws and strategies working at the local levels of government (John, 2006).

Refined dialogues and reliable debates on the benefits and negative characters of explicit arranging process for citizens' participation are truly non-existent, despite the fact that 'community interest' includes as a key part of arranging process at the grassroots. To put it plainly, doubtlessly the bureaucratic elites of authorities and councillors are resolved to force, their own truncated form and knowledge of 'citizen's interest' on the specific community (Tshoose, 2015). This exceptionally decayed nature of 'interest' is by all accounts working absolutely on the grounds that in the South African rendition of vote based system of democracy, the political party is everything. That is the body of the electorate (political party) is nothing aside from when and just it is required to vote in favour of an explicit political party (Madzivhzndila and Maloka, 2014). Tshoose further stated that South Africa is not practising a constituency-based system of democracy; instead, it is a partybased system of government. Where subject vote in favour of the political party and not for explicit individuals. Thus, the exercise prevails where chosen authorities can truly 'cross the floor' abandoning one party for another without the residents having much to say, if any use, to stop such floor-crossing. Such a constrained type of majority rules system of democracy offers to ascend to a managed society.

As opposed to a law based society, as the assent for administration isn't earned through strategy discussions of the points of interest, and inconveniences of explicit social developments. However, political passive consent is fabricated through the skilful control of a large group of research organizations, so-called specialists, sentiment surveys (Tshoose, 2015). At the point when most of the people in country territories are able to do any of financial versatility (improvement), it tends to be reasoned that development has achieved the majority of its nationals (Dwi et al., 2017). Alongside the difference in globalization, the advancement of a worldview that was initially more accentuation on financial improvement is currently beginning to be deserted in light of the fact that it can't tackle social issues, for example, destitution or eradication of poverty, juvenile misconduct, and monetary inconsistencies. The development on the worldview has started to move toward community approach, in which already community network was as an object of advancement turn into a subject of advancement. The new advancement paradigm is more aligned toward community network based improvement, by giving a focal place to activities of local assorted variety, and local insight (Dwi et al., 2017). A community commitment to participate in local governance can take numerous structures, and accomplices can incorporate an organized group of people, offices, establishments, or people (Tshoose, 2015). Partners might be occupied with wellbeing advancement, research, or strategy making (Wallerstein, 2002).

'Community engagement can also be seen as a continuum of community involvement in local governance. Over time, a specific collaboration is likely to move along this continuum toward greater community involvement, and any given collaboration is likely to evolve in other ways, too' (CFCA, 2016). The objectives of community commitment to participate in local governance are to "build trust, enlist new resources and allies, create better communication, and improve overall wellbeing of the general public outcomes, as successful projects evolve into lasting collaborations" (Shore, 2006; Wallerstein, 2002). The accentuation on community commitment has energized "social wellbeing" of people in a given social order, community pioneers, and strategy creators to envision new open doors as they confront new difficulties (Doll et al., 2008). Besides, people's commitment is grounded in the standards of community association: reasonableness, equity, strengthening, interest and participation, and self-assurance (Alinsky, 1962; Chávez et al., 2008; Freire, 1970; Wallerstein et al., 2002). This study reviews the literature in understanding the dynamics of community engagement in local Governance, in enhancing South African Grassroots Development through community participation in the decision-making process in local government. This article develops the ideas, models, and systems that can be utilized as a guide and move activities to address different basic challenges identifying with community participation.

\section{Literature Review}

Community Engagement: The commitment of the community to participate in local governance requires interest of community individuals in projects that address their issues. Important or a "meaningful community participation extends beyond physical involvement to include generation of ideas, contributions 
to decision making, and sharing of responsibility" (John, 2006). Among the components that spur individuals to take an interest need to assume a functioning job in bettering their very own lives (Fung, A. 2015) and satisfying social or religious commitments feeling a requirement for a feeling of the network in the community and pursuit for economic empowerment or in-kind rewards (Tshoose, 2015). The absence of shared regard and co-learning may result in loss of time, trust, assets or resources, and, above all, adequacy and effectiveness (Henry, 2011; Minkler et al., 2009). The "social exchange" viewpoint gives knowledge into inspirations to the investment of interest, according to Levine et al. (1961), it utilizes the structure of advantages and expenses to help clarify who partakes and why. From this point of view, associations and people are engaged with an "exchange framework" and wilfully share assets to meet their objectives. Community individuals and associations will only take an interest on the off chance that they see that the advantages of cooperation to participate in local government, administration exceed the exertion required, (Butterfoss, 2006; Bradford, 2016). However, the literature investigating the participatory role of the general(spelling) public propose that participatory procedures and frameworks in South Africa need transformative characteristics and are defaced by a blend of disregard, absence of administration conveyance, defilement of corruption, infrequent feedback, restricted contribution and naiveté with respect to organizers and authorities (Lues 2014:802-804).

The lack of access to information, for example, is said to be lacking and uneven, similar to the limits of residents (and authorities) to comprehend the specialized organizations in which information is exhibited (Houston 2001:207:278). The support that occurs will, in general, be brief, in the state of sporadic data sources that enhance specific phases of arranging and programming cycles. When they do happen, inputs are spurring of the moment (Friedman 2006:8:11). Pundits have scrutinized the gravity with which citizen and community cooperation is being grasped in the local government practice (Buccus and Hicks, 2006:2). The accentuation, they contend, is set on meeting different execution targets and administration conveyance necessities, with an open investment of interest by the community highlighting as a member to those needs (Betancourt et al., 2016). At the local circle, the local government authorities will, in general, go about as guardians and controllers as opposed to as facilitative bodies that empower citizens and community to have a more prominent voice and command over assets and asset portion. The districts are blamed for being either reluctant or unfit to share the basic leadership control with networks of community, particularly in connection to extend distinguishing proof. Systems are equipped fundamentally towards looking for networks of citizens in the community' to contribute to an effectively defined arrangement reactions.

The observation among individuals from the network community is that open participation of the community, if and when it happens, it includes the introduction of foreordained positions and projects for constrained input or for the purpose of information sharing (Nomdo et al., 2018). Actually, when a network of community inputs are requested, they usually joined by poor assistance of the participatory procedures. A key to successful investment of interest by the community can be dictated by the readiness with respect to government to be available to subjects when all is said in done and the poor specifically. The poor can't pick up a voice through organized invested interest to participate in discussions since they are normally complicated and they come up short on the ability to take an interest (Friedman 2006:8, 11). A considerable lot of the poor don't take an interest in grassroots survivalist associations in light of the fact that the legislature does not give participatory spaces in which they will be allowed to convey what needs (Friedman 2006:8, 11). In a perfect ideal world, the formation of these law based spaces is intended to empower customary masses to draw in with the legislature from an enabled position where they can have their voices heard. As far as the more extensive open discourse is concerned, Theron and Mchunu (2013:106) and van Kempen (2014:201) noted that participatory spaces will give chances to fortify the relationships among government and subjects and upgrade responsibility among government delegates, common society and nationals.

The clashing idea of participatory and representatives vote based system of democracy runs its course while the electorate condemns the apparent inclusion of the normal masses and the eliteness of the activity of open power by elected delegates. Of grave concern is the way that picking up entry into these spaces does not at all outcome in the modification of intensity chains of command that would truly enable the minimized citizens to take part substantively, consequently ensuring that their voices will be heard. The potential advantages of investment of interest to participate in local governance for the community individuals, scholastics, and 
wellbeing experts incorporate open doors for systems administration, access to information and assets, individual acknowledgment, taking in, a feeling of tackling the issues of the community, enhanced connections among partners, expanded limit with regards to critical thinking, and contact with difficult toachieve populaces (Butterfoss, 2006). The procedure of social, monetary and political change to engage and fortify the limit of the network community through a participatory learning process, so as to change conduct in all partners, which are associated with the advancement procedure. This is to understand a progressively engaged, free, and increasingly prosperous and feasible participatory. The development of the community is an idea of monetary advancement which that embodies social qualities.

This idea mirrors the new worldview paradigm of advancement, which is "individuals focused, participatory, enabling, and practical" (Chambers, 1994). This idea is more extensive than simply satisfying fundamental needs or giving instruments to avert further security net, in which this idea has as of late been created as an endeavour to discover options towards the past development. This idea created by the endeavours of numerous specialists and experts to discover elective improvement. Friedmann (2006) characterizes elective improvement as wants "comprehensive majority rules system of democracy, suitable monetary development, sexual or gender uniformity and intergenerational value". While exploring on the way to deal with understanding a network of community participation in more noteworthy profundity, a virtual viewpoint of 00few community are mapped onto geologically characterized territories, however today, people depend increasingly more on the use technologies like the computers and handset devices interceded interchanges to get to information, engage with individuals, and settle on choices that influence their lives online (Kozinets, 2002).

Instances of computers intervened types of correspondence incorporate email, moment or content informing, electronic chat rooms, and person to person communication sites, for example, Facebook, YouTube, and Twitter (Flavian et al., 2005; Kleinhans et al., (2015). Likewise, a feeling of membership of a network community can change after some time and may influence their interest in networking exercises. Today, the various community networks that may be significant for any individual-including families, work environment, social, religious, and political affiliations-propose that people are contemplating themselves in more perplexing routes than it was the standard in years past. The qualification criteria that researchers and approach authors produce for social projects and research ventures reflect one way that individuals see a gathering of proposed members, however, how much of those criteria mirror the members' real perspective is uncertain. The supporters of community commitment attest that it enhances peaceful coexistence, advance security among network of individuals (Flavian et al., 2005). However, the procedures, costs, and advantages of community participation are as yet a generally new field of study.

\section{Methodology}

The approach adopted in this research is a qualitative analysis as a suitable research method. Data are collected from numerous secondary bases predominantly from journal article, reports from government and non-government organizations and book source. Over 80 sources were consulted but only 70 were found relevant to the study. The researcher basically used documentary analysis which allows researchers to study and makes sense of written documents, which may be available either in public or private domain (Mogalakwe, 2006). It is recommended, that researchers determine the relevance of the documents consults on the basis of their significance to the study. Furthermore, Dey $(2005: 105)$ argues that "in a written analysis, the criteria for selecting documents, or for focusing on particular extracts, should reflect the issues on which the researcher is seeking evidence." This method, therefore, made it possible to explore various existing literature on the field of study with understanding the concept and the dynamics of community Engagement in local governance, enhancing Grassroots Development in the municipality.

\section{Theoretical Consideration of Community Model}

The discourse on the community, there is certainly a multifaceted discourse on the issues of community support and the need to take part in local governance. Therefore one need to think about numerous intricacies around community interests. In the area of improved collaboration, the expression "community" is frequently utilized in a geological sense, as a gathering of individuals living respectively in a town or chiefdom 
turning into the subject of field study. Nonetheless, the idea of "community" goes past this spatial measurement. As stated by Hunter 12 (1975:538), there are three unique measurements that can establish a network: "(1) space, (2) social relations, or (3) personality." In the participatory talk on community interest to participate in local governance appears to be regularly seen as something that is remotely energized. "Local gatherings are distinguished" (Minkler, Wallerstein and Wilson, 2008:287). Their objectives by outside characters, which are "giving over the stick' of power" (Chambers 1994:1255). This brings up the issue of office. Furthermore, who has the ability to share it or pass it on? This sort of discourse disregards the likelihood that communities are engaging themselves in empowering them to approach outside characters on eye-level-a thought that is caught under Arnstein's eighth classification of "native control". While Lennie (1999) points out that the topic of office is imperative to the idea of strengthening, which generally can be an outflow of "a shrouded paternalism in the help office" (chamber 1994:200 referred to in Lennie, 1999:103).

Regarding social relations, Etzioni (1996:5) contends that in a "community" these are more than "one-on-one relations". Or maybe, the huge number of interconnections between individual relations shapes an interpersonal organization that rises above the insignificant whole of the individual relations. While it is conceivable to concentrate on every one of these measurements independently, networks of community are generally comprised by an interchange of at least two of them. In this manner, the expression "community" in this study will be comprehended as a multidimensional idea as proposed by Hunter (1975). It is essential to not see a community therefore as a homogenous gathering, as people can be a part in few community networks at the same time, converting into various personalities, jobs and interests, which can be conflicting. In any case, the meanings of the term 'community' fluctuate generally crosswise over various fields of study. Culture is another component that has affected Community Engagement. An anthropologist Katz (2007), characterized culture as 'a complex coordinated arrangement of thought and conduct shared by individuals from a gathering-a framework whose entire example enables us to comprehend the implications that individuals append to explicit certainties and perceptions'.

Culture shapes personalities and cultivates ideas of community networks, and it shapes how people and gatherings identify with one another, how significance it is made, and how control is characterized. Moreover, culture shapes thoughts regarding association, trust, and negotiation. Therefore, culture shapes the procedure of community commitment to participate in local governance, and powerful commitment requires a comprehension of culture (Ginev, 1998). Specifically, scientists and specialists need to comprehend the social elements of explicit gatherings and organizations so as to construct the connections, distinguish approaches to viably work together, and create regard and trust; This is a progressing exertion for all associated with the "community engagement process" (Minkler, 2004). As earlier said above, community are not homogeneous substances; they are comprised of assorted gatherings with various accounts, social structures, values frameworks, and social understandings of the world. There is a drive in social change to enhance hierarchical straightforwardness and responsiveness, and this has the ability to impact the local community.

What is Community Engagement Exactly? There is no straightforward or single response to the inquiry on 'what is community engagement?' It resists definition since to everybody; it appears, has an alternate answer (CFCA, 2016). Things being what they are, who gets the chance to choose? In this section, it investigates the issue from the viewpoint of few unique disciplines trying to concoct a bound together, a comprehensive, definition that enables the majority of the callings to "claim" community engagement to commit all things. The inquiry presently is what are the advantages of community commitment to engage in local governance? One advantage likely to get from community commitment or engagement is the ability to connect with the "under-represented groups." The generally quiet larger part bustling individuals the online network community. A great number of people won't go to an open gathering. Those that do for the most part have a valid justification; which means they will, in general, hold a solid view somehow on a specific issue.

As a rule, a small gathering of individuals have an exceptionally solid view and normally endeavour to overwhelm every other voice with the goal that their view may win. The general population who don't have a solid view basically don't persuade an opportunity to be heard. An exact discovery demonstrates that community commitment help to settle on better choices. There are two essential motivations to attempt community commitment. There you have the optimist, who trusts that it is the proper activity. The practical 
person trusts it prompts better choices. The distinction being that on the grounds that online network community commitment enables you to contact more individuals, it is increasingly viable in overseeing hazard, testing presumptions, and being a decent national. Besides, citizenry commitment can advance network possession and likewise help to uncover the main problems and worries in the community through a forum called "deliberative politics" (CFCA, 2016).

The Importance of Community Engagement: Discussing community engagement, there is a scope of reasons why it ought to be an imperative component of future administration development, at the municipal grassroots dimension, in connecting with the citizens give them feeling of obligation, as well as make a sentiment of obligation. Community engagement is a method for guaranteeing that individuals approach valued social settings and exercises, feel that they can contribute genuinely to those exercises commitments, and create useful abilities that empower them to take part completely in municipal matters. It might be that the intricacy of the issues in a portion of these network communities is with the end goal that conventional ways to deal with tending to the issues have been incapable.

We can't realize what these networks of the community require without better understanding their goals, concerns and qualities within the community by engaging with the community member directly (CFCA, 2016). The engagement of the community can assume an imperative job in this regard. The general population benefit reform motivation cannot succeed basically by the top down inconvenience or the imposition of unified targets or more market-based decision (2020 Public Services Trust, 2010; Commission on the Future Delivery of Public Services, 2011). That is, if the government neglect to move to an association way to deal with client (the community members) directions, they will turn out to be progressively ineffectual at accomplishing their objectives. Another important reason of justification to engage with the community is that, it can prompt enhanced results for the community for a "substantive legitimization" (Burton et al., 2006). The above statement supports the community to search out the goals, concerns and estimations of the community.

They are therefore able to share their desires, concerns and values with establishments; and these yearnings, concerns and estimations of the community are therefore consolidated into basic leadership forms through decision-making process. It makes the foundations better ready to address the issues of the community basically because of being better educated. Building up a compelling association between administration frameworks and the community results in a more prominent feeling of possession more prominent take-up of administrations and better results for children and families, (Yeboah, 2005). It would thus prompt enhanced results for the community because of mediations and methodologies that are custom-made to the "unique aspirations" or desires, concerns and values of that "community" (Reddel and Woolcok, 2004). As to the meaning of community engagement or commitment in this study, the majority of the interest to participate is engaged with the procedures that would be accomplished by the standards of respectability, integration, consultation, and impact.

Community Engagement as a Human Right: In community engagement, there is rights-based contention for community commitment and cooperation. For example, the United Nations-supported Brisbane Declaration on Community Engagement (International Conference on Engaging Communities, 2005) recognizes the general intrigue and significance of engaging with the community, established in the "inherent dignity of people and the values", rights and obligations surprisingly communicated in the Universal Declaration on Human Rights (p. 1). The proof to show its adequacy, it could be contended that community commitment, that is, the procedure whereby general society adds to basic leadership forms - is a central civil right. To be sure, advocates of this view hold that "community engagement" is the way to participatory for all citizens - instead of only representative in a democratic system of government. A community engagement mirrors the privilege of ordinary citizens to be associated with administration going beyond the polling station and an important consistent exchange among governors and the represented (Khan, 2005; Shore et al., 2006). Collectively, these are some of the reasons signifying an incredible method for the utilization of community engagement methodologies in administration development.

What are the Challenges of Community Engagement? One of the difficulties in guaranteeing representativeness is the manner by which to guarantee that those community individuals whose voices are 
heard are illustrative of the network. As Katz (2007) brought up the point that not all individuals can take part in projects to a similar degree, and numerous intercessions effectively include just a few individuals (despite the fact that the entire network is relied upon to profit), How do community members or individuals effectively take an interest by volunteering to join the board committees, and as such speak to different individuals from their community? For members to be illustrative of the more extensive network, it is important either that they are chosen or that they relate to it and has its interests on the most fundamental level. The following are likely challenges faced in engaging with members of the community and getting them involved in municipal administration; guaranteeing equity value -communities are mixed. Specific consideration should be taken to guarantee that the less incredible voices and gatherings are locked in and not undermined. It, therefore, implies that including leaders of various group or organisations, individuals with handicaps, youth, individuals from non-English-speaking foundations and Indigenous individuals within the communities. There is a problem of establishing community views - "One can seek to establish community views by summing the separate opinions of individual community members (e.g., via surveys) or by seeking to establish the collective views of community members (e.g., by focus groups or community forums)" (Simpson et al., 2003). Soliciting excessively from individuals from the community -in trying to include the people in basic leadership in decision-making process and associations there is a risk of soliciting excessively from them, causing pressure and weariness (Attree et al., 2011; Simpson et al., 2003).

It is additionally imperative to abstain from making community activities excessively subordinate upon a couple of leaders, as opposed to building limit capacity over a wide scope of people. Staying away from disappointment is another issues or challenge in engaging the community members. As a result, community members may wind up disappointed if the "community engagement process" does not a prompt activity that mirrors their concerns. It is basic that the proficient administrations included are to be completely dedicated to the procedure, willing and ready to react to the choice or agreement reached. A foremost obstruction to poor or sabotaged individuals getting to be associated with activities to address destitution is a vulnerability (van Kempen 2014:201). Conquering past abysmal encounters can likewise be an issue: few communities might be hesitant to be included on the off chance that they have been frustrated by previous activities which they see to have exhibited few advantages (Cortis et al., 2009). Different difficulties incorporate the accompanying: The test of setting up administration courses of action.

For people's commitment and associations to wind up standard practice and reasonable they should be inserted in continuous administration game plans. It is not sensible to have a community representation at all dimensions of government; it should be defined clearly at the grassroots. Basically, the government's job is to make the conditions that permit the administrations they store to connect adequately with those they serve. That incorporates giving administrations a level of adaptability to react to the rising needs of the community and being willing to respect and bolster the choices arrived at by the organization forms by the community. Changing proficient practice is recognized as another challenge, that is, studies of how well experts can convey family-focused practice have appeared that there is constantly a gap between the talk and reality. Making people's commitment a standard practice in human administrations requires a change in perspective in the idea of the connection among authority and the governed, governments and citizens, benefit frameworks and networks (Dunston et al., 2009).

An Empirical Findings on Community Participation: Participatory improvement motivation on the agenda is scrutinized for being excessively debated and lacking important operationalization and execution on the ground and in addition adequate observational or "empirical evidence" (Rudqvist and Woodford-Berger 1996:1). Universal establishments are blamed for paying lip-administration to the idea as a method for coselecting communities for their own advantage and authenticity (Akerkar 2001:1, 2; Arnstein 1969:216). Mosse (2001:19) presumes that participatory procedures conceal outside plans, which will in general decide the results of those procedures. A fascinating contention made by Cornwall (2003a) is that in as much as the participatory discourse may be about strengthening and consideration of minimized gatherings into tasks influencing their lives, the functional acknowledgement stays with the contemporary "narratives of improved collaboration. It in this way keeps on loaning itself "to compatibility with neoliberal improvement motivation "agendas in which fundamental questions of structural, intersubjective and personal power remain unaddressed". Power is a focal viewpoint and support should dependably be found in light of intensity relations (Rifkin 1986:243). On intra-community level, Adam and Oshima (2014:25) feature that 
underestimated gatherings like the youths have been truly rejected out rightly excluded from basic leadership power with regards to decision-making and they alert to deliberately consider the conceivable effects of investment on solidified power.

The community elites generally overwhelm participatory procedures, as a result of built up conventional jobs, as well as "they will, in general, be better instructed" and "have less open door costs on their time" (Mansuri and Rao 2003:42). Concerning outside establishments, Merzel and D'Afflitti (2003:566) declare that there are regularly clashing interests in participatory ventures, where control relations are consulted on unequal terms as power over assets and issue choice more often than not rest with the outer organization. This identifies with the issue that most communities in participatory undertakings will, in general, be basically included at the usage phase of activities. Substantially less so in the regions of necessities evaluation/issue determination or project plan (Merzel and D'Afflitti, 2003:559) an overview of a research conducted in Zambia on community engagement demonstrated that only about $22 \%$ of the respondents felt that the social assets of the 1990s, which were imagined to incorporate dimensions of network meeting and investment, tended to the key issues recognized by the community themselves (Binswanger-Mkhize et al., 2010:45). Against this foundation, different writers featured that the instrumental way to deal with interest with an attention on results and adequacy is considerably more far reaching than the more transformative methodology (Walsh et al., 2012:10; Harman, 2009:300). Be that as it may, it has been brought up that there is minimal observational and empirical proof supporting the cases of expanded productivity or viability of participatory methodologies (van Kempen, 2014:201).

Some even contend that support diminishes cost adequacy of activities and "the rhetoric fuels hopes that cannot be met in practice" (Lamb et al., 2005:185; Walsh et al., 2012:2). Besides, the instrumental methodology, where most communities are included as methods for expanding authenticity, proficiency or, truth be told, control, as "fuse, as opposed to avoidance, is frequently the best methods for control" (White 1996:7), has been censured as shallow and undermining the transformative capability of participatory methodologies (Cornwall 2003:1326; White 1996:7). In any case, one needs to recognize a situation that accompanies the transformative way to deal with interest, which esteems of local learning and the neighbourhood "method for getting things done" without forcing an untouchable's motivation (Mohan and Stokke 2000:252).

\section{Conclusion and Recommendations}

Conclusively this study noted that the basic reason for having a community engagement is the "underlying community participation. The process where a community directly participate in local governance with the commitment of community members in the issues of planning, administration, basic leadership of making decisions and the general improvement process at grassroots, which has recently turned into an essential part of democratic practice. On such account in South Africa where local citizens interest to participate in local government administration has actually turned out to be synonymous with genuine governance. Incontrovertibly, there are number of elements fundamental to community engagement. Considering the underlying community needs in developing their communities, there is needs to establish a strong instrumental understanding of the dynamics of participation in local government decision-making process and in more transformative approaches where the community has actual decision-making power in the community project to various degrees." The elements of community cooperation in local government using South Africa as a focal example, it originally offered a narrative of the development of thought and practice in public interest to participate in local governance and the present accentuation on citizen-led responsibility.

It recognized a portion of the key constraints in the ebb and flowed discourse on citizen-led responsibility activities, contending for an exploration plan that deals with real community issues. Considering the manysided difficulties looked by the government in its push to enhance public support, it turns out to be evident that there is a need to enhance the systems for public cooperation and participation. The districts or municipality must set up support instruments that are accommodative of a wide range of individuals in their regions. Community engagement has been viewed as a continuum increasing level of community Involvement, impact, trust, and communication flow. Some community involvement communication streams from one to the next. Commitment by the community makes chances to enhance the assent procedure, 
distinguish moral entanglements, and make forms for settling moral issues when they emerge. Engaging the members of the community can increase improved learning, a higher profile in the community, more linkages with other community individuals, and new influential capacity. Regions ought to be guided by authoritative prescripts to guarantee straightforwardness and responsibility in the administration of their undertakings.

Besides, people should review challenges related with gathering politicization of improvement and participatory structures, the absence of responsibility towards organizing community interest, the absence of limit capacity among partners, poor access to data, and inability to perceive and work intimately with network-based associations. South African municipality should check whether the community and different partners have taken part in the discussions that prompted the last record, as this is required by the Municipal Structures Act. It is suggested that the jobs of various partners amid the interest procedure must be settled on. The time allotments for public and partners reactions, information sources and remarks must be given. The municipality's correspondence procedure must be actualized in manners that empower the cooperation of chaotic gatherings. The method must have clear techniques to guarantee investment amid the diverse periods of arranging. The way to gather data on community network should likewise be plainly laid out in the correspondence technique. It is prescribed that open interest must be organized so as to guarantee that individuals in the local Municipality have an equivalent ideal to take an interest.

\section{References}

2020 Public Services Trust at the RSA. (2010). From social security to social productivity: A vision for 2020 Public Services. The final report of the Commission on 2020 Public Services.

Adam, S. G. \& Oshima, K. (2014). Engaging Youth through Community Driven Development Operations Experiences, Findings, and Opportunities, Global Stocktake Synthesis Paper, World Bank, Washington.

Akerkar, S. (2001). Gender and Participation - Overview Report, Institute of Development Studies, Brighton.

Alinsky, S. D. (1962). Citizen participation and community organization in planning and urban renewal. Chicago: Industrial Areas Foundation; 1962.

Arnstein, S. R. (1969). The Ladder of Citizen Participation. The Journal of the Royal Town Planning Institute, 35(4), 216-224.

Attree, P., French, B., Milton, B., Povall, S., Whitehead, M. \& Popay, J. (2011). The experience of community engagement for individuals: A rapid review of evidence. Health \& Social Care in the Community, 19(3), 250-260.

Betancourt, D. S., Vivier, L. E. \& Piper, L. (2016). Preliminary assessment of public participation (PP) and community engagement (CE) in the city of Cape Town: developing a framework for strengthening participation. HSRC.

Binswanger-Mkhize, Hans P., Aiyar S. S., Anklesaria, de Regt., Jacomina, P., Serrano-Berthet, Rodrigo, H., Louis Van Domelen, J., Warren D. \& Spector, S. (2010). Historical Roots and Evolution of Community Driven Development, in Binswanger-Mkhize, Hans P.; de Regt, Jacomina P. \& Spector, Stephen (eds.) (2010): Local and Community Driven Development-Moving to Scale in Theory and Practice, The World Bank, Washington, D.C

Bradford, A. (2016). Community engagement and local government. University of Wollongong. Unpublished Masters by Research. School of Management Operations and Marketing.

Buccus, I. \& Hicks, J. (2006). Assessing the effectiveness of community based involvement. Critical Dialogue: 2.

Burton, P., Goodlad, R. \& Croft, J. (2006). How would we know what works? Context and complexity in the evaluation of community involvement. Evaluation, 12(3), 294-312.

Butterfoss, F. D. (2006). Process evaluation for community participation. Annual Review of Public Health, 27, 323-340.

Centres for Disease Control and Prevention (CDC). (1997). Principles of community engagement (1st Ed.). Atlanta (GA): CDC/ATSDR Committee on Community Engagement; 1997.

CFCA. (2016). Community Engagement. A key strategy for improving outcomes for Australian families. CFCA Paper No. 39 - April 2016.

Chambers, R. (1994). Participatory rural appraisal (PRA): Analysis of experience, in World Development, 22(9), 1253-1268.

Chávez, V., Minkler, M., Wallerstein, N. \& Spencer, M. S. (2008). Community organizing for health and social justice. In: Cohen L, Chávez V, Chehimi, S. (editors). Prevention is primary: strategies for community well-being (1st Ed, pp95-120). San Francisco: John Wiley and Sons; 2007. 
Commission on the Future Delivery of Public Services. (2011). Report on the Future Delivery of Public Service. Edinburgh, Scotland: Commission on the Future Delivery of Public Services.

Cornwall, A. (2003a). Whose Voices? Whose Choices? Reflections on Gender and Participatory Development, in World Development, 31(8), 1325-1342.

Cornwall, A. (2008b). Unpacking 'Participation': models, meanings and practices, in Community Development Journal, 43(3), 269-283.

Cortis, N., Katz, I. \& Patulny, R. (2009). Engaging hard-to-reach families and children, Occasional Paper No. 25. Canberra, ACT: Department of Families, Housing, Community Services and Indigenous Affairs.

Dey, I. (2005). Qualitative Data Analysis. London: Routledge, Taylor and Francis Group.

Doll, L. S., Bonzo, S. E., Mercy, J. A., Sleet, D. A. \& Haas, E. N. (2008). Handbook of injury and violence prevention (2nd Ed.). Atlanta (GA): Springer; 2008.

Dunston, R., Lee, A., Boud, D., Brodie, P. \& Chiarella, M. (2009). Co-production and health system reform - from re-imagining to re-making. The Australian Journal of Public Administration, 68(1), 39-52.

Dwi, W., Wahjoedi, M. E., Sri, U. M. W. \& Mit, W. (2017). The Dynamics of Community Participation in Developing Tourism Village at Monomerto, Wonosalam, Jombang District. IOSR Journal of Humanities And Social Science (IOSR-JHSS), 22(8), 11-17.

Etzioni, A. (1996). The Responsive Community: A Communitarian Perspective, 1995 Presidential Address, in: American Sociological Review, 61, 1-11.

Flavian, C. \& Guinaliu, M. (2005). The influence of virtual communities on distribution strategies on the internet. International Journal of Retail \& Distribution Management 2005, 33(6), 405-425.

Freire, P. (1970). Pedagogy of the oppressed. New York: Herder and Herder; 1970.

Friedman, S. (2006). Participatory governance and citizen action in post-apartheid South Africa. Paper for International Institute of Labour Studies, 8-11.

Fung, A. (2015). Putting the Public Back into Governance: The challenges of Citizen Participation and its future. Public Administration Review, 75, 4.

Ginev, D. (1998). Rhetoric and Double Hermeneutics in the Human Sciences, in Human Studies, 21, 259-271.

Glavaš, D. (2017). Political advertising and media campaign during the pre-election period: A Comparative Study. Commissioned by the Organisation for Security and Co-operation in Europe (OSCE) Mission to Montenegro.

Harman, Sophie. (2009). Bottlenecks and Benevolence: How the World Bank is Helping Communities to 'Cope' with HIV/AIDS, in Journal of Health Management, 11(2), 297-313.

Henry, S. G. (2011). The tyranny of reality. JAMA, 305(4), 338-339.

Houston, G. (2001). The social dynamics in public participation in legislative processes in South Africa in Public participation in democratic governance in South Africa. Houston, G. (eds.) Pretoria: Human Sciences Research Council, 207-278.

Hunter, Albert. (1975). The Loss of Community: An Empirical test Through Replication, in American Sociological Review, 40(5), 537-552.

International Conference on Engaging Communities. (2005). The United Nations (Brisbane) declaration on community engagement. Brisbane, Queensland: Queensland Government.

John, J. W. (2006). Community Participation: Lessons from South Africa. Policy Studies, 27, 3.

Katz, I. (2007). Community interventions for vulnerable children and families: Participation and power. Communities, Children and Families Australia, 3(1), 19-32.

Khan, U. (2005). Participation beyond the ballot box: European case studies in state-citizen political dialogue. London: Routledge.

Kleinhans, R., Van Ham, M. \& Evans-Cowley, J. (2015). Using Social Media and Mobile Technologies to Foster Engagement and Self-Organisation in Participatory Urban Planning and Neighbourhood Governance. Journal of Planning Practice \& Research, 30, 3.

Kozinets, R. V. (2002). The field behind the screen: using ethnography for marketing research in online communities. Journal of Marketing Research, 39(1), 61-72.

Lamb, R. D., Varettoni, B. \& Shen, C. (2005). Participatory Development and the World Bank, in International Affairs Review, 14(2), 171-194.

Lennie, J. (1999). Deconstructing Gendered Power Relations in Participatory Planning: Towards and Empowering Feminist Framework of Participation and Action, in Women's Studies International Forum, 22(1), 97-112. 
Levine, S. \& White, P. (1961). Exchange as a conceptual framework for the study of inter-organizational relationships. Administrative Science Quarterly, 5(4), 583-601.

Lues, L. (2014). Citizen participation as a contributor to sustainable democracy in South Africa. International Review of Administrative Sciences, 80(4), 802-804.

Madzivhzndila, T. S. \& Maloka, C. M. (2014). Community participation in local government planning processes: A paramount step towards successful service delivery. Mediterranean Journal of Social Sciences, 5, 16.

Mansuri, G. \& Vijayendra, R. (2003). Evaluating Community-Based and Community-Driven Development: A Critical Review of the Evidence, Development Research Group, the World Bank, Washington.

Merzel, C. \& D'Afflitti, J. (2003). Reconsidering Community-Based Health Promotion: Promise, Performance, and Potential, in American Journal of Public Health, 93(4), 557-574.

Minkler, M. \& Wallerstein, N. (2009). Community-based participatory research for health: from process to outcomes. Health Promotion Practice, 10(3), 317-318.

Minkler, M. \& Pies, C. (1997). Ethical Issues in community organization and community participation In Minkler M (editor). Community organizing and community building for health (1st Ed, pp116-133) Piscataway (NJ): Rutgers University; 1997.

Minkler, M. (2004). Ethical challenges for the "outside" researcher in community-based participatory research. Health Education and Behavior, 31(6), 684-697.

Mogalakwe, M. (2006). Research Report. The Use of Documentary Research Methods in Social Research African Sociological Review, 10(1), 221-230.

Mohan, G. \& Stokke, K. (2000). Participatory development and empowerment: the dangers of localism, in Third World Quarterly, 21(2), 247-268.

Nomdo, A., Davis, Y. D. \& Betancourt, D. S. (2018). Community Engagement and the Provision of Water Services in Nyanga, Cape Town. HSRC.

Reddel, T. \& Woolcok, G. (2004). From Consultation to participatory governance? A critical review of citizen engagement strategies in Queensland, 63, 3.

Rifkin Susan, B. (1986). Lessons from community participation in health programmes, in: Health Policy and Planning, 1(3), 240-249.

Rudqvist, A. \& Woodford-Berger, P. (1996). Evaluation and Participation-some lessons, Sida Studies in Evaluation 96/1, Department for Evaluation and Internal Audit, Stockholm.

Shore, N. (2006). Re-conceptualizing the Belmont Report: a community-based participatory research perspective. Journal of Community Practice, 14(4), 5-26.

Simpson, L., Wood, L. \& Daws, L. (2003). Community capacity building: Starting with people not projects. Community Development Journal, 38(4), 277-286.

Theron, F. \& Mchunu, N. (2013). Contextualising public protests, the case of Khayelitsha. Administration Publica, 21(2), 106.

Tshoose, C. I. (2015). Dynamics of public participation in local government A South African perspective. African Journal of Public Affairs, 8, 2.

UNDP. (2004). Rapid Appraisal of the Community capacity empowerment Programme and Leadership Development for Results components of the Enhancing Integrated Response to HIV, AIDS and Poverty programme. UNDP: Pretoria.

Van Kempen, L. (2014). Mansuri, Ghazala and Rao, Vijayendra: Localizing development. Does participation work? Book Review, in Journal of Economics, 112(2), 201-205.

Wallerstein, N. (2002). Empowerment to reduce health disparities. Scandinavian Journal of Public Health Supplement, 59, 72-77.

Walsh, A., Mulambia, C., Brugha, R. \& Hanefeld, J. (2012). The problem is ours; it is not CRAIDS'. Evaluating sustainability of Community Based Organisations for HIV/AIDS in a rural district in Zambia, in Globalization and Health, 8(40), 1-16.

White, S.C. (1996). Depoliticising development, the uses and abuses of participation, in Development in Practice, 6(1), 6-15.

World Health Organization (WHO). (1991). Community Involvement in Health Development: Challenging Health Services-Report of a WHO Study Group, in WHO Technical Report Series, 809, WHO, Geneva.

Yeboah, D. A. (2005). A framework for place-based health planning. Australian Health Review, 29(1), 30-36. 